\title{
Múltiplas Recidivas Oligometastáticas em Doente com Tumor de Pulmão Não-Pequenas Células
}

\section{Multiple Oligometastatic Recurrences in a Patient with Non-Small Cell Lung Cancer}

Orlando Nunes ${ }^{1}$, Leonor Abreu Ribeiro¹, Julieta Silva², Cepeda Ribeiro³, António Pinto Marques $^{4}$, Luís Mestre ${ }^{5}$, Sara Turpin ${ }^{6,7}$, Paula Borralho7, Manuela Bernardo ${ }^{1}$

\section{RESUMO}

O tumor de pulmão não-pequenas células apresenta-se em estádio precoce, claramente cirúrgico, apenas em cerca de $20 \%$ dos casos. No entanto, até metade destes doentes vêm a recidivar sistemicamente, com rápida progressão de doença. Nalguns casos, no entanto, o padrão de metastização é limitado a um órgão, com um pequeno número de lesões (1-5) correspondendo ao conceito de recidiva oligometastática ou oligoprogressiva. Com tratamento local agressivo, têm sido documentadas longas sobrevivências nestes doentes, sugerindo uma biologia particular.

Apresenta-se o caso de uma doente jovem, com recidiva de adenocarcinoma primário do pulmão oligoprogressiva, mas múltipla, na mama, pele e sistema nervoso central, dois, 12 e 27 meses após cirurgia curativa, tratada localmente com cirurgia e gamma knife, com longa sobrevivência e mantendo-se clinicamente assintomática.

PALAVRAS-CHAVE: Carcinoma Pulmonar de Células não-Pequenas; Metástases Neoplásicas; Processos Neoplásicos

\section{ABSTRACT}

Surgical stages of non-small cell lung carcinoma represent only about $20 \%$ of all cases. However, $50 \%$ of these patients will relapse after surgery, with metastatic disease and dismal prognosis.

In some cases, the pattern of relapse is oligometastatic - a limited number of lesions (1-5) on a single organ (oligoprogressive if there is a short interval after surgery).

With aggressive local treatment, long survivals have been documented in these patients, suggesting a particular biology.

The authors present the case of a young woman with multiple oligoprogressive relapse of a primary pulmonary adenocarcinoma, (breast, skin and central nervous system) two, 12 and 27 months after curative lung surgery, treated locally with surgery and gamma knife, with a long survival and keeping clinically asymptomatic.

KEYWORDS: Carcinoma, Non-Small-Cell Lung; Neoplasm Metastasis; Neoplastic Processes

1. Oncologia, Hospital CUF Infante Santo, Lisboa, Portugal. 2. Radioterapia, Hospital CUF Descobertas, Lisboa, Portugal. 3. Pneumologia, Hospital CUF Infante Santo, Lisboa, Portugal. 4. Cirurgia Cardio-Torácica, Hospital CUF Infante Santo, Lisboa, Portugal. 5. Senologia, Hospital CUF Infante Santo, Lisboa, Portugal. 6. Anatomia Patológica, Hospital SAMS/Lab M Luz Roriz, Lisboa, Portugal. 7. Anatomia Patológica, Hospital CUF Descobertas, Lisboa, Portugal.

Recebido: 09/05/2017 - Aceite: 31/08/2017 


\section{INTRODUÇÃO}

Os tumores de não-pequenas células do pulmão constituem cerca de $80 \%$ do total, apresentando-se na maioria dos casos como doença localmente avançada ou metastizada.

Mesmo nos casos considerados cirúrgicos na altura do diagnóstico, (cerca de 20\%) quase metade vem a recidivar, na maioria de forma disseminada ${ }^{1}$ (polimetastática), sendo o tratamento considerado paliativo e consistindo em quimioterapia, agentes biológicos ou terapêuticas-alvo, ou mais recentemente, imunoterapia.

No entanto, alguns doentes apresentam-se com uma situação definida como recidiva oligometastática - metastização à distância limitada a 1-5 lesões locorregionais ou num único órgão, num tumor primário controlado e permitindo sobrevivências mais longas ou mesmo cura. ${ }^{2}$

Nos casos em que há um intervalo curto entre a cirurgia do tumor primário e a recidiva, pode ser denominada de doença oligoprogressiva. ${ }^{3}$

Mais recentemente surgiu ainda o conceito de doença oligometastática síncrona, correspondendo a um número limitado de metástases (1-5) mas sem tratamento prévio do tumor primário. ${ }^{4}$

Apresenta-se o caso clínico de uma doente com diagnóstico de carcinoma do pulmão não-pequenas células, em estádio IB operado, com várias recidivas oligometastáticas abordadas com tratamento local. A doente mantém-se assintomática e livre de doença mais de 10 anos após o diagnóstico inicial.

\section{CASO CLÍNICO}

Doente do sexo feminino, leucodérmica, 43 anos, com carga tabágica de cerca de 40 unidades-maço-ano.

Referia queixas de tosse e toracalgia direita com cerca de um mês de evolução. Foram efetuados exames, incluindo tomografia computorizada (TC) de tórax, que revelou área de condensação nodular no lobo superior do pulmão direito, adjacente à pleura parietal axilar, com 15 mm de diâmetro, espiculada, sem condicionar retração ou derrame pleural. Não havia evidência de outros nódulos pulmonares nem de adenopatias hilares ou mediastínicas.

A tomografia de emissão de positrões (PET), confirmou um único foco hipermetabólico ( $3 \times 2 \mathrm{~cm})$, com SUV máximo de 4,2. A ressonância magnética (RM) cranioencefálica não revelou quaisquer imagens suspeitas de metastização.

Clinicamente estadiada como cT1 cNO MO, (estádio IA)

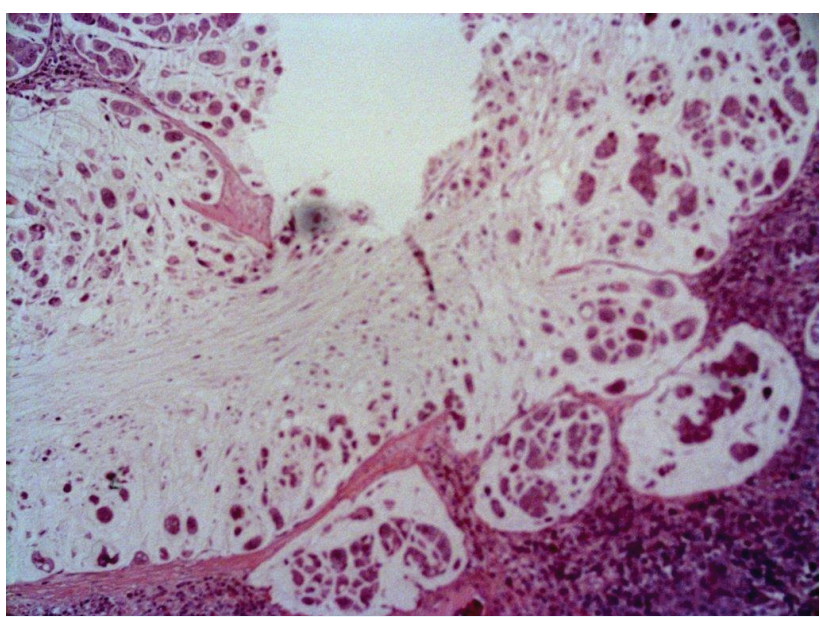

FIGURA 1A. Biópsia de tumor do pulmão: adenocarcinoma do pulmão (coloração HE)".

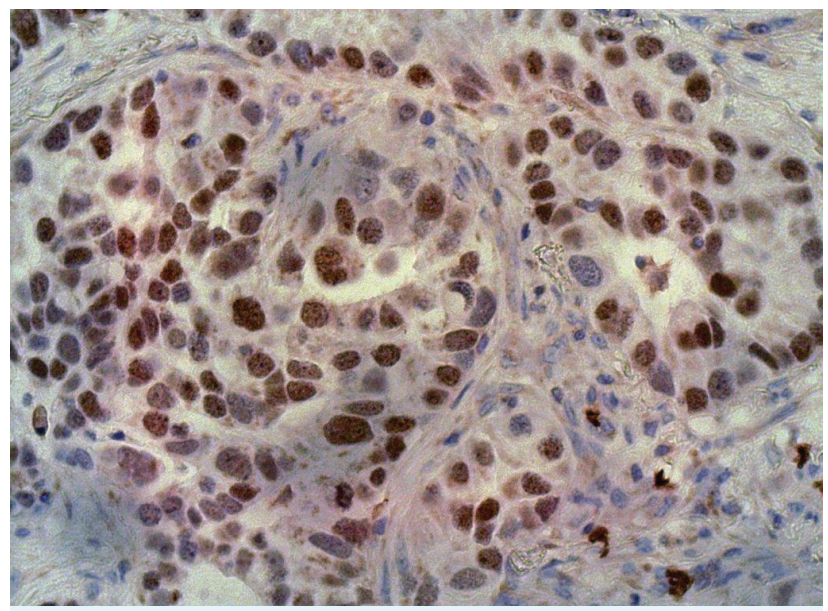

FIGURA 1B. Biópsia de tumor do pulmão, marcação com TTF1.

foi submetida a lobectomia superior direita um mês após o diagnóstico.

O exame anatomopatológico confirmou adenocarcinoma, CK7, MNF116 e TTF1 positivos, com 3,5 × 1,5 × 1,2 $\mathrm{cm}$, moderadamente diferenciado, com focos de diferenciação mucinosa (10\%) e de necrose. O tumor invadia a pleura, sem romper o mesotélio, com invasão vascular; isolados quatro gânglios do hilo, sem metástases: pT2a, pNO - estádio IB (Fig.s 1 A e B).

Posteriormente foi efetuada pesquisa de mutações EGFR, que foi negativa.

Não foi efetuado tratamento adjuvante.

O único sintoma aquando da primeira observação em Oncologia Médica era dor neuropática intensa pós-toracotomia, a nível do hemitórax direito, tendo a doente sido observada e medicada em consulta de dor.

Cerca de dois meses depois, a doente notou a presença de nódulo do quadrante súpero-externo da mama esquerda, móvel e duro. Fez mamografia que confirmou tratar-se de nódulo único, sem adenopatias axilares sus- 
peitas e depois microbiópsia, que confirmou presença de células epiteliais malignas, compatível com adenocarcinoma. Foi submetida a tumorectomia um mês depois.

O exame anatomopatológico revelou tratar-se de adenocarcinoma com 6 mm de diâmetro, AE1/AE3 e TTF1 positivos, recetores hormonais negativos, compatível com metástase mamária de tumor primitivo do pulmão.

Repetiu TC e PET que excluíram outras localizações suspeitas.

Dado nunca ter efetuado terapêutica sistémica, foi proposta quimioterapia com paclitaxel e carboplatina, tendo o tratamento sido interrompido após três ciclos por neurotoxicidade > G2. Os exames então efetuados continuavam a não mostrar lesões suspeitas e a doente ficou de novo em vigilância.

Doze meses após a cirurgia inicial, notou aparecimento de nódulo subcutâneo no terço médio da face posterior da coxa esquerda, indolor, móvel, e duro, com cerca de $3 \mathrm{~cm}$. O re-estadiamento voltou a não sugerir outros locais de doença, tendo sido submetida a ressecção do nódulo.

O exame anatomopatológico revelou de novo adenocarcinoma com 2,5 cm de diâmetro, compatível morfologicamente com metástase de tumor primitivo do pulmão, confirmando assim a segunda recidiva isolada da doença (Fig.s $2 \mathrm{~A}$ e B).

No decurso da vigilância médica posterior, foram descritas em TC opacidades de topografia subpleural no lobo médio e lobo superior esquerdo, no contexto suspeitos de corresponder a novos focos de doença.

Foi decidido proceder-se a ressecção atípica do lobo superior esquerdo. No exame anatomopatológico, o diagnóstico foi de fibrose, inflamação crónica inespecífica, hemorragia e focos de enfisema, sem tecido de neoplasia.

Manteve-se sob vigilância médica e cerca de nove meses depois mantendo-se assintomática, nova TC revelou lesão nodular de aparecimento de novo, no lobo inferior esquerdo, com características imagiológicas compatíveis com novo depósito secundário.

Foi de novo submetida a ressecção pulmonar atípica do LIE, incluindo fragmento de pleura parietal. $\bigcirc$ exame anatomopatológico revelou mais uma vez inflamação crónica, hemorragia e pneumonia organizada, também sem evidência de tecido neoplásico.

Quatro meses após a última intervenção, a doente sofreu uma lipotimia. Quando foi observada estava já vígil, orientada e colaborante, sem sinais focais do sistema nervoso central (SNC). Efetuou TC-CE, que revelou uma lesão parenquimatosa cortical, frontal anterior es-

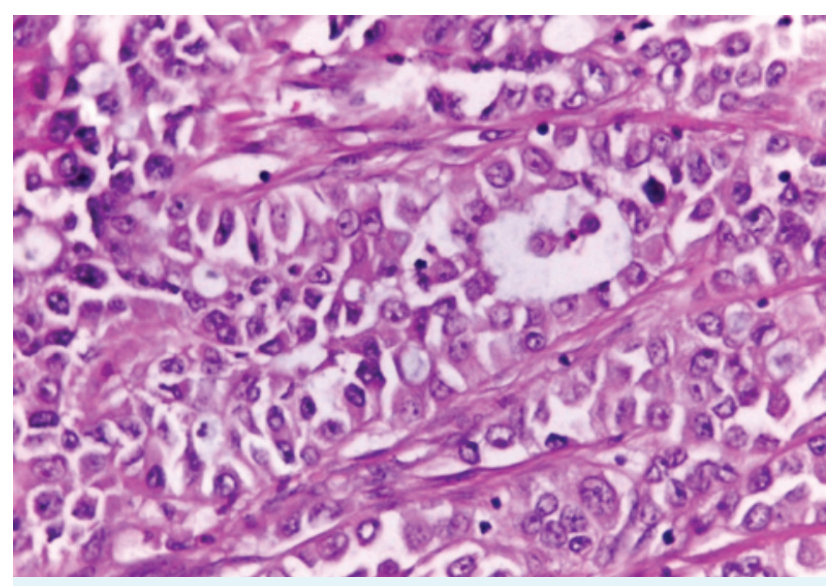

FIGURA 2A. Infiltração de tecidos moles por adenocarcinoma, com padrão morfológico consistente com neoplasia primitiva do pulmão.

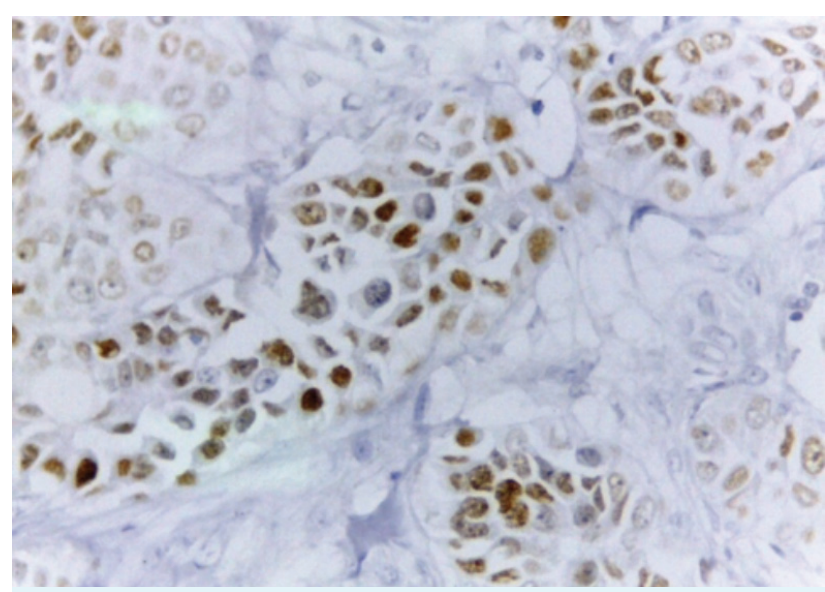

FIGURA 2B. Estudo IHQ com TTF1 revela positividade nuclear, confirmando metástase de adenocarcinoma do pulmão.

querda, e outra, de características semelhantes, parietal interna direita. Havia edema vasogénico associado, mas sem hemorragia.

Estas lesões foram confirmadas em RM-CE, não havendo confirmação histológica, mas admitindo-se metastização. Tinham entretanto surgido mais dois nódulos subcutâneos, na face dorsal do pé direito e região inguinal esquerda.

Decidiu-se proceder a tratamento com gamma knife (Hospital CUF Infante Santo) - 22 Gy sobre cada uma das lesões cerebrais.

No mês seguinte, em junho de 2009, foram excisados os nódulos subcutâneos, cuja histologia revelou nódulos fibrosos, fibro-lipomatosos, sem presença de células malignas.

Desde aí a doente foi progressivamente recuperando a sua capacidade de desempenho das atividades pessoais e posteriormente profissionais.

À data da última observação na Consulta de Oncologia (praticamente 10 anos desde o diagnóstico), encontra- 
va-se completamente assintomática, sem sinais clínicos, laboratoriais ou imagiológicos de recidiva.

\section{DISCUSSÃO}

O conceito de doença oligometastática foi definido nos anos 90 por Hellman e Weichselbaum, ${ }^{5}$ como um estádio intermédio entre a doença limitada e metastizada, embora, desde há décadas, doentes com número limitado de metástases tenham vindo a ser tratados com ressecção cirúrgica e/ou radioterapia. ${ }^{6-7}$

Estas entidades têm vindo a merecer mais atenção nos últimos anos devido ao aparecimento de técnicas de imagem mais sofisticadas, permitindo a identificação mais precoce das lesões, bem como a tratamentos mais eficazes que aumentam a longevidade dos doentes. ${ }^{8}$

Nos últimos anos, tem-se tentado avaliar a frequência, evolução clínica e fatores de prognóstico nesta população. Num estudo japonês publicado em 2016,9 com um total de 768 doentes, a recidiva oligometastática ocorreu em 21\%, com incidências que vieram a aumentar gradualmente ao longo dos anos. Os locais mais frequentes foram o cérebro, pulmão, gânglios, suprarrenal e osso. Os melhores resultados ocorreram em doentes com uma única recidiva. Comparativamente com a doença polimetastática, tinham estadiamento mais precoce no diagnóstico e intervalo livre de doença superior.

Em termos biológicos, pensa-se que, dada a heterogeneidade das populações celulares no tumor primário, esta situação surja quando o clone metastático tem menor potencial de agressividade. ${ }^{10}$ Yachida et al ${ }^{11}$ utilizaram técnicas de NGS (next generation sequencing) em doentes com tumores do pâncreas, sugerindo na tumorigénese a presença de clones com menor agressividade, muitos anos antes do aparecimento de outros que originam a doença polimetastática.

Os avanços na investigação dos genes que regulam a metastização tumoral têm também contribuído para a melhor compreensão destas entidades, nomeadamente a análise de DNA arrays, apesar de não haver ainda uma clarificação sobre quais os genes responsáveis pelo fenótipo oligometastático.

Wuttig et $a^{12}$ demonstraram, em amostras de metástases pulmonares de tumores de células renais, a presença de 135 genes expressos de modo diferente nas situações oligo e polimetastáticas. Nestas últimas foram ainda detetados genes envolvidos na regulação do ciclo celular.

A doente descrita tem atualmente mais de 10 anos de evolução de um adenocarcinoma primário do pulmão, operado em estádio IB.

A primeira recidiva ocorreu dois meses depois, a nível da mama esquerda; a segunda recidiva, após 12 meses, em tecidos moles da coxa esquerda e já depois de ter feito tratamento sistémico, ambas operadas com ressecção completa. A terceira recidiva, 15 meses após a anterior, ocorreu a nível cerebral, tendo nesta altura, já 27 meses sobre o diagnóstico inicial, tendo-se optado por fazer apenas radiocirurgia.

É de realçar que as lesões pulmonares que foram detetadas posteriormente não correspondiam a metástases, ao contrário do que o diagnóstico inicial e a evolução da doença permitiria supor.

Como pontos fracos, desconhecemos a presença de mutações de outros genes para além do EGFR, então não disponíveis. Não temos documentação histológica da recidiva no SNC, não se tendo optado por cirurgia devido ao facto de ter ocorrido pouco tempo depois da última toracotomia e já com a presença de outros nódulos subcutâneos, sugerindo uma generalização da doença metastática, o que felizmente não foi confirmado.

A abordagem cirúrgica das lesões pulmonares sem biópsia prévia tem a mesma fundamentação.

Trata-se de um caso de clara recidiva oligometastática, com a particularidade de esta ser múltipla, no tempo e em órgãos diferentes, mas comprovando o benefício da terapêutica com intenção curativa, com ênfase nos tratamentos locais. A quimioterapia poderá ter tido influência positiva na erradicação do clone maligno.

A resiliência desta doente foi também notável, com total aderência aos tratamentos propostos, recompensada provavelmente com a cura da doença.

CONFLITOS DE INTERESSE: Os autores declaram não ter qualquer conflito de interesse na realização do presente trabalho.

FONTES DE FINANCIAMENTO: Não houve qualquer fonte de financiamento na realização do presente trabalho.

CONFIDENCIALIDADE DOS DADOS: Os autores declaram ter seguido os protocolos da sua instituição acerca da publicação dos dados de doentes.

PROTEÇÃO DE PESSOAS E ANIMAIS: Os autores declaram que os procedimentos seguidos na elaboração do presente trabalho estão em conformidade com as normas das comissões de investigação clínica e de ética, bem como da declaração de Helsínquia e da AssociaçãoMédica Mundial.

CONFLICTS OF INTEREST: The authors declare that they have no conflicts of interest.

FINANCIAL SUPPORT: This work has not received any contribution, grant or scholarship. 
CONFIDENTIALITY OF DATA: The authors declare that they have followed the protocols of their work center on the publication of data from patients.

PROTECTION OF HUMAN AND ANIMAL SUBJECTS: The authors declare that the procedures followed were in accordance with the regulations of the relevant clinical research ethics committee and with those of the Code of Ethics of the World Medical Association (Declaration of Helsinki).

\section{REFERÊNCIAS}

1. Uramoto $H$, Tanaka F. Recurrence after surgery in patients with NSCLC. Transl Lung Cancer Res. 2014;3:242-9.

2. Niibe $Y$, Hayakawa K. Oligometastasis and oligo-recurrence: the new era of cancer therapy. Jpn J Clin Oncol. 2010;40:107-11.

3. Richard P, Rengan R. Oligometastatic non-small-cell lung cancer: current treatment strategies. Lung Cancer. 2016;7:129-40.

4. Niibe $Y$, Chang JY. Novel insights of oligometastasis and oligo-recurrence and review of the literature. Pulm Med. 2012;2012:261096.

5. Hellman S, Weicheselbaum RR. Oligometastasis. J Clin Oncol. 1995;138-10
6. Rosenberg SA. Surgical treatment of metastatic cancer. Philadelphia: Lippincott Williams \& Wilkins; 1987.

7. Rubin P, Green J. Solitary Metastases. Springfield: CC Thomas; 1968.

8. Reyes D, Pienta K. The biology and treatment of oligometastatic cancer. Oncotarget 2015;11:8491-524.

9. Hishida T, Yoshida J, Aokage K, Nagai K Tsuboi M. Postoperative oligo-recurrence of non-small-cell lung cancer: clinical features and survival. Eur J Cardiothorac Surg. 2016;49:847-53.

10. Huang F, Wu G, Yang K. Oligometastasis and oligo-recurrence: more than a mirage. Radiat Oncol. 2014;9:230.

11. Yachida S, Jones S, Bozic I, Antal T, Antal T, Leary R, Fu B, et al. Distant metastasis occurs late during the genetic evolution of pancreatic cancer. Nature. 2010;467:114-17.

12. Wuttig D, Baier B, Fuessel S, Meinhardt M, Meinhardt M, Herr A, Hoefling C, et al. Gene signatures of pulmonary metastases of renal cell carcinoma reflect the disease-free interval and the number of metastasis per patient. Int J Cancer. 2009;125:474-82. 